Editorial

\title{
Sincere Thanks
}

Andreas Böning

Thorac Cardiovasc Surg Rep 2015;4:1.

With this print issue of the Thoracic and Cardiovascular Surgeon Reports (TCSR), it is time to say "Thank you" to different groups of people having accompanied the TCSR so far:

"Thank you" to the authors who consigned their articles to the TCSR, although many of them had to be disappointed by a "reject" decision for their article. Partly the articles were unsuited for our surgical journal, partly the articles had no news to report to the scientific community, and partly the articles were written in a confusing language that could be remotely considered as being English. The 2015 acceptance rate of scientific case reports was $42 \%$, although it would have been $100 \%$ in a nonpeer-reviewed journal with a financial instead of a scientific interest. The 2016 publication fee for an article in TCSR is $998 €$ with a discount for members of the German Society for Thoracic and Cardiovascular Surgery (499€).

"Thank you" to the editorial staff of our publisher for always being a help to the editor. We are pleased to announce that TCSR will, from mid/late November 2015, be searchable in the Web of Science (WOS) database. This is a great achievement, which means not only that is our journal now going to be searchable on WOS but also that it has passed the first hurdle to being awarded an Impact Factor.

"Thank you" to our reviewers for fast, insightful, unpaid reviews. The "top reviewer" for this journal made 10 assessments during this year! 